\title{
Inspired Oxygen Fraction Test
}

National Cancer Institute

\section{Source}

National Cancer Institute. Inspired Oxygen Fraction Test. NCI Thesaurus. Code C38082.

A test to evaluate amount of oxygen taken up by arterial blood and expressed as a fraction of total oxygen of inspired air. This test may include other test such as pulse oximetry for the measurement of arterial blood oxygen levels. 